\title{
Simulations of Manufacturing Systems: Applications in Achieving the Intended Learning Outcomes
}

\author{
Paweł Litwin, Maksymilian Mądziel, Dorota Stadnicka \\ Faculty of Mechanical Engineering and Aeronautics, Rzeszow University of Technology, \\ Al. Powstancow Warszawy 12, 35-959 Rzeszow, Poland \\ \{plitwin,mmadziel, dorota.stadnicka\}@prz.edu.pl
}

\begin{abstract}
The work describes various problems that can arise in the planning, organization and operation of manufacturing processes. The consequences for the companies resulting from the problems are deliberated together with the proposed remedies. It is important to teach students what kind of problems they may face in their future work and how they can analyze the problems and look for appropriate solutions. The students should also understand how the problems can influence on other companies working in a collaborative network $(\mathrm{CN})$. In the work, the intended learning outcomes that can be achieved are presented. Then, simulations of chosen problems are analyzed and discussed.
\end{abstract}

Keywords: industrial problems, simulations, intended learning outcomes.

\section{Introduction}

The manufacturing technologies fast development and dissemination enforces a necessity of quick knowledge acquisition by companies current and future employees. Therefore, adequate learning tools and methods such as simulations [1], [2] virtual reality [3] or social networks [4] have to be engaged. For each educational program not only teaching methods but also methods using for students' knowledge verification are important [5]. Also companies adapt different learning means, since their employees' knowledge and skills have to be improved continuously. The employees learn to understand better the problems and to know which tools should be applied to solve the problems.

Manufacturing processes (MPs) planning and organization concern many issues that should be analyzed starting from understanding of customers' requirements and ending with customers' satisfaction assessment. The main goal of MPs is to produce on time the ordered quality products. Low quality or delivery delays can cause collaborators to choose another company, that is able to deliver required products. Additionally, since, the clients' requirements can change in time, the manufacturing lines (MLs) has to be adapted. In a collaborative world the problems, which arise in one company can affect other companies in a network. Since, a CN consists of a variety of entities geographically distributed, operating in different environment, having different culture [6], a risk connected with the collaboration can be high. The 
companies deal with different problems which can influence on a ML operation and potentially on collaborators. Quality issues cause reworking, scraps, delays and waiting and are analyzed with the use of quality tools [7] and six sigma projects [8]. Machine failures cause stoppages, waiting, delays, nonconforming products and can be minimized by TPM implementation [9]. Materials delivery delays cause waiting, high material inventory levels. These causes can be minimized by implementation of supermarkets, Kanban System, Just in Time [10]. Clients' requirements changes cause scraps and technology changes. These negative consequences can be minimized by improvement of communication system. Excessive work in process causes long lead time, what can be minimized by Supermarkets, Kanban System or FIFO implementation [11]. Unfortunately not all of the problems can be eliminated. Therefore, a company, knowing the scale of the problems, can make a manufacturing system resistant to the troubles to protect client.

This paper is focused on simulation applications in educational process concerning problems that can arise in or influence management of MPs and which can potentially influence company's collaborators in a network. The authors propose an approach based on simulations involving a set of steps to analyze the problems. The goal of this approach is to teach effectively students the methods that can be used in such analyses.

\section{Simulations Applied in Educational Process}

System Dynamics (SD) is a method of modeling and simulation systems containing causal relationships with their logic, time delays and feedback loops. Researchers inspired by successful applications of the SD method in various fields (management, engineering, physics, economy) began to apply the SD approach also in the field of teaching and learning. Students can use SD models to perform experiments, which can be easily repeated using various parameters and alternative scenarios. In many cases, the simulation is the only available way to observe the results of the experiment. The first applications of the method in schools showed that SD, in addition to the benefits of understanding cause-and-effect relationships, helps increase students' involvement in voluntary projects, even after school time [12]. As a result of the positive adoption of the SD method to schools, a number of educational projects have been developed. Jay Forrester indicates the three main benefits that the SD method used in education gives [13]: (1) develops personal skills such as clarity of thought for good communication, courage for having unconventional opinions; (2) shapes an outlook and personality to match the challenges of the 21st century; (3) allows to understand the nature of systems in which we work and live. This paper presents examples of the third benefit, in particular related to the modeling of supply chain (SC).

The use of the SD method for simulation of the SC dates back to the second half of the 20th century. Model of the production and distribution system to which the "Forrester Supply Chain" (FSC) label is attached [14] was the subject of many research works. An overview of research on SC, including, among others, SC design, inventory management, demand amplification, and SC reengineering is presented in 
[15]. The SD method was also used to study the impact of the information flow model on the level of stocks of enterprises collaborating in the SC [16].

Discrete event simulation (DES) is another commonly used modelling technique [17]. This kind of simulation is an operative research technique that has a great potential to help understand the analyzed system. One of the advantages of using DES over other mathematical models is the simulation capability to model complex flow scenarios [18]. One of the tool which can be applied in DES is Flexim. Flexsim is a virtual mapping of a real system based on real data. It allows to conduct simulation experiments and check different variants of solutions. It is an attractive tool in the student education process because it gives the opportunity to analyze visually modelled object parameters and material flow in real time. Students working in this program may partly feel like in a computer game in which they have a strictly defined goal to achieve. Flexsim software is used for simulation of transport processes, storage and delivery as well as for production-manufacturing purposes [19]. Examples of using the Flexsim program for simulation purposes are widely presented in works [20], [21]. The use of this program in such a number of industries gives a signal to universities to use it also in the process of student education. Flexsim allows to check the results of calculations in simulation, which gives students additional visual control of the correctness of their calculations. An example of works that describe the use of Flexsim software in the field of student education are presented in [22]. The mentioned works justify the simulation application in educational process in the context of collaborative networks analyses.

\section{Case Studies}

$\mathbf{1}^{\text {st }}$ Problem description: In the MP nonconforming products can be identified. It can happen on different stages of a MP. A nonconforming product might be reworked or will be a scrap. Quality level of a MP can be described with the use of First Time Yield (FTY) or First Pass Yield (FPY) [2]. The measures can be calculated on the base of historical data.

Consequences of the $\mathbf{1}^{\text {st }}$ problem: If a product can be reworked, it will go back to the previous process and use additional time for the repeated manufacturing operation. If a product will be a scrap, all previous MPs have to be repeated. It creates additional costs and can lead to delivery delays and clients dissatisfaction what even can lead to exclusion the company from a $\mathrm{CN}$.

Proposed solutions or remedies: To improve the quality on a MP TQM can be implemented. The employees can be involved in identification of quality problems and they can propose solutions connected with better work organization, product or process design etc. That can lead to decreasing quality problems.

Proposed analyses: The analyses proposed for such problems concern assessing how nonconformities can influence on a MP and affect deliveries. For this purpose, DES simulations taking into account FTY and FPY, will be carried out.

Intended learning outcomes:

ILO1: Identify potential consequences of nonconforming products, which can be 
reworked or scraps, in a specified processes in a ML

ILO2: Use standard measures such as FTY and FPY in simulations.

ILO3: Understand how a place (a work stand) in which a nonconforming product is identified influences on lead time increasing.

Case study description: The case study presents situation in which a ML consisted of 4 MPs which manufactures three kinds of products operates. In Processes 1,2 and 3 operators make a quality control after the machining process. Then, after the Process 4 all products go to the control process (Process 5) performed on a coordinate measuring machine (CMM). Initial quality parameters are presented with the use of FTY and FPY. FTY is connected with the products which are assessed to be scraps. FPY is connected with the products which have to be reworked. The input data are presented in Table 1. Tact time equals $15 \mathrm{~min}$. The production material is available from the beginning of the simulation and is released every 15 minutes. First material delivery is realized at time $t=0$. The ML works for first shift only. Available working time equal $450 \mathrm{~min}$.

Table 1. Data concerning the ML; PT - proc. time, QI - values after quality improvement.

\begin{tabular}{lllllll}
\hline Process & PT [min] & Setup [min] & FTY & FPY & FTY-QI & FPY-QI \\
\hline Process 1 & 30 & 0 & 0.92 & 0.95 & 0.93 & 0.96 \\
Process 2 & 30 & 0 & 0.95 & 0.90 & 0.96 & 0.91 \\
Process 3 & 30 & 0 & 0.98 & 0.95 & 0.99 & 0.96 \\
Process 4 & 10 & 5 & 0.90 & 0.88 & 0.91 & 0.89 \\
Process 5 & 5 & 10 & - & - & - & - \\
\hline
\end{tabular}

The number of products that should be delivered to the customer every day is 30 pcs (10 pcs. of each type). The order of performing different types of products is random. Setups are needed only for Processes 4 and 5 on which all three kinds of products are treated. Processes 1, 2 and 3 are dedicated to one type of the product.

Computer model development: Computer model of the ML was developed in Flexim software.

Simulation scenarios: Students perform simulations for the following scenarios:

Scenario Q1: A simulation under predetermined parameters and ML organization before quality improvement.

Scenario Q2: A simulation in which the ML works also for the second shift, with the same tact time $15 \mathrm{~min}$.

Simulation results: Simulations allow to obtain the following results (Table 2).

Table 2. DES simulation results - machine load (ML), average inventory level (AIL), product average stay time in input and output inventories of the processes (AST).

\begin{tabular}{lllllll}
\hline Process & ML [\%] & AIL [pcs] & AST [min] & ML [\%] & AIL [pcs] & AST [min] \\
\hline \multicolumn{7}{l}{ Scenario Q1 } \\
\hline Before Process 1 & - & 3.8 & 33.2 & - & 6.4 & 54 \\
Process 1 & 100 & 4.2 & 82.3 & 96.6 & 8.1 & 82.2 \\
Process 2 & 100 & 4.2 & 82.3 & 96.6 & 8.1 & 82.2 \\
Process 3 & 80 & 4.2 & 82.3 & 89.9 & 8.1 & 82.2 \\
Process 4 & 62.2 & 2.3 & 25.2 & 64.4 & 4.9 & 55.2 \\
Process 5 & 30 & 0 & 0 & 31.7 & 0 & 0 \\
\hline
\end{tabular}


Average Lead Time (ALT) for Q1 equals 203.5 min. A number of good quality products manufactured in a working day (QC) equals 24 pcs. Time required to manufacture 30 pcs (TR) equals $555 \mathrm{~min}$. For Q2 ALT equals $284 \mathrm{~min}$ and during 2 shifts 46 pcs of QC are produced.

Discussion and proposed solutions: Performed simulations show that the solution that meets the production assumptions $(30 \mathrm{pcs})$ is Scenario Q2, which consisted of extending the work and adding a second shift in production. The Q1 does not meet the production requirement. If the solution with the second shift was to be considered, other pros and cons of this solution should be deliberated, such as economic analysis, etc. This state of affairs also encourages the student to think and search for another effective solution that would fully meet the assumptions of the work task, because the Q2 exceeds the demand for the products. Students are motivated to propose and implement other changes to the ML to see their influence on the results.

$2^{\text {nd }}$ Problem description: Pull systems require feedback between supply and demand for production volume planning, and simulation can be very helpful in these cases [23]. Presented problem concerns parts and products flow between a supplier, a producer, a retailer and a client, and illustrates the formation of so-called bullwhip effect, which consists of transferring reinforced changes in demand through the SC.

Consequences of the $2^{\text {nd }}$ problem: Relatively small fluctuations in the demand reported by the customers increase as the information is communicated upstream to the producer and further to the supplier. Information transferred in the form of orders through the SC does not actually reflect changes in demand on the retail market, but contains a number of decisions regarding inventories. This can cause excessive stocks in the SC.

Proposed solutions or remedies: To deal with this problem the companies can, implement modified replenishment policy or redesign the information flow that will improve inventory management throughout the SC.

Proposed analyses: The activities proposed for this problem concern the assessment of the impact of demand fluctuations and stock replenishment policies on the volume of stocks in individual parts of the SC.

Intended learning outcomes: In simulations students are able to obtain the following intended learning outcomes:

ILO1: Identify potential consequences of bullwhip effect in SC.

ILO2: Assess the impact of demand fluctuations on stock levels in SC.

ILO3: Propose a solution that avoids excessive stock in the SC.

Case study description: The case study presents application of SD method for analyzing the stocks in the SC. The supplier is responsible for the delivery of parts to the manufacturer. The producer manufactures finished products using parts from the supplier. These products are transferred to the retailer and then to customer. The customer's task is to generate demand and collect products delivered by the retailer. Variability of demand is considered one of the main factors responsible for the formation of the bullwhip effect. The effect lies in strengthening demand changes carried upstream the SC. The information is falsified: besides the actual changes in demand it includes the replenishment policy decisions. In the analyzed SC model shaping the level of inventories is based on the assumption that the demand in the next period will be the same as demand in the current period. 
Replenishment is only carried out when the level of inventory is lower than required. Formula (1) presents the method of determining the amount of the parts order by the producer:

$$
\text { po }=\operatorname{IF} \text { THEN ELSE }((p p<2 * p q), 2 * p q-p p, 0)
$$

where: po - parts ordered, pp - parts stock at producer, pq - production quantity

The advantage of the presented formula is its simplicity, however, it has some drawbacks. The selected inventory replenishment policy assumes demand unchanged. In business practice, this assumption may cause some problems. If the demand in the next period decreases significantly - the result will be an excessive accumulation of goods in the SC, and hence an increase of storage costs. There may also be a situation when the demand for the next period will be much higher than the current demand. The result of such a situation will be extended time of order fulfillment.

Computer model development: A modified version of FSC (Fig. 1) contains stocks of supplier, producer retailer and customer. The model shows the impact of the adopted procurement strategy on the levels of stocks of collaborating enterprises.

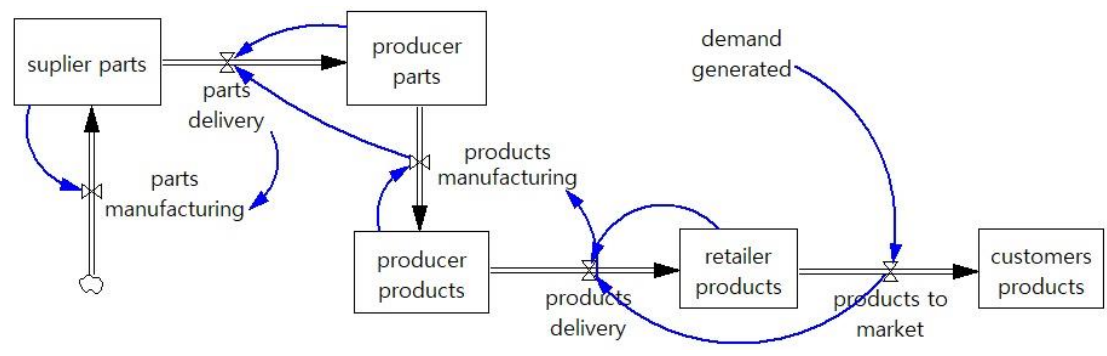

Fig. 1. The structure of the tested SC in Vensim.

This study presents the application of the SD method for analyzing SC stock levels in conditions of constant and variable demand. Inventory levels are analyzed over a period of 250 days.

Simulation scenarios: In experiments, 3 demand distributions were considered:

Scenario D1 - Constant daily demand of 5 pcs.

Scenario D2 - Random normal distribution (mean -5 pcs, st. dev. -1.6 pcs.).

Scenario D3 - Random uniform distribution.

In D2 and D3, integer pseudo-random numbers in the range $(0-10)$ are generated as the demand values. For all scenarios, initial stock levels of 3 pcs. were established.

Simulation results: After a short period of simulation the levels of all stocks in D1 scenario stabilized at $5 \mathrm{pcs}$. The longest period of inventory stabilization concerns the supplier's stock and amounts to 6 days. The maximum level of the supplier's inventory ( 19 pcs.) is achieved on the second and third day of simulation.

In the D2 scenario, the variability of demand caused changes in stocks in individual parts of the SC. Changes in stock of the part supplier were particularly large. The average supplier stock was $16 \mathrm{pcs}$. and the maximum reach $38 \mathrm{pcs}$. 
The feature of D3 scenario is strongly variable demand. This resulted in a reinforcement of the bullwhip effect. Maximum retailer's stock level was 44 pcs. and the mean value was 25 pcs. (Fig. 2).

suplier parts

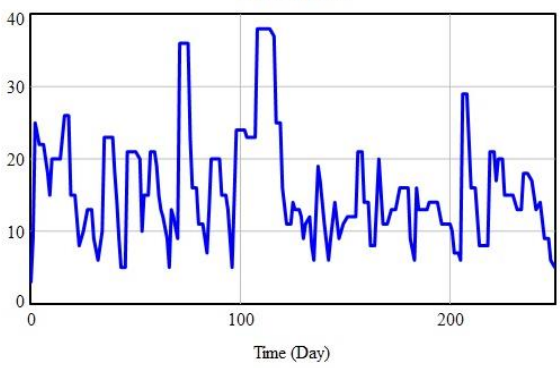

retailer products

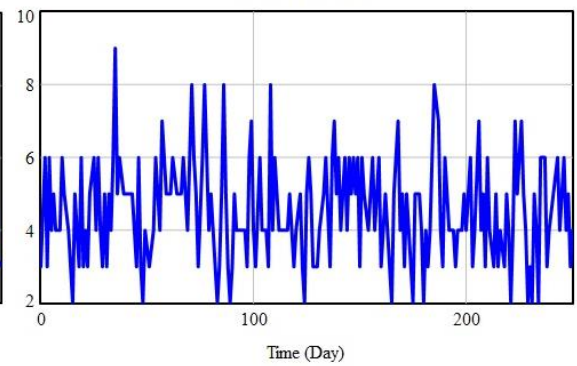

Fig. 2. Stocks of the supplier's and retailer. Random normal demand distribution.

The simulation results indicate that the intensity of the bullwhip effect increases with the increase in demand variability. The presented simulations can be used for educational purposes as an effective tool for demonstrating the bullwhip effect. Additionally, with the ability to modify the model, students can implement other stock replenishment policies and examine their impact on stock levels. Finally, students assisted by the teacher can redefine the way of information flows so that each link in the SC uses data on the current market demand. As demonstrated in [17], this will significantly reduce the bullwhip effect and its impact on stock levels.

\section{Summary}

The presented work deals with simulations which can be applied in didactic processes to achieve the specified ILOs what is the main paper contributions to the science. The presented approach consisted of a set of steps ensure deep understanding of problem consequences and allow to find the best solution. Additionally, such way of analyses increase students creativity, as they want to check many different solutions, since it is easy to do in computer simulations. Additionally, the students realize that the companies are not the isolated islands and operate in CNs. Being a part of $\mathrm{CN}$ gives the company opportunities but also creates responsibilities. The mistakes such as quality issues and delivery delays can cause the company exclusion from a network.

In the future work the authors will also investigate other problems that can be analyzed with the use of simulations and create educational case studies with indicated ILOs. Additionally, in the future works the authors are planning to add another step to the presented approach that is Design of Experiment (DOE), which will allow to look for an optimal solution of an analyzed problem.

Acknowledgments. This work has been partially supported by the "TIPHYS 4.0 Social Network based doctoral Education on Industry 4.0", project No 2017-1-SE01KA203-03452 funded by ERASMUS+ of the European Commission. 


\section{References}

1. Antonelli, D., D'Addona, D.M., Maffei, A., Modrak, V., Putnik, G., Stadnicka, D., Stylios, C.: Tiphys: An open networked platform for higher education on Industry 4.0. Procedia CIRP, vol. 79, pp. 706-711 (2019)

2. Stadnicka, D., Litwin, P.: Value stream mapping and system dynamics integration for manufacturing line modelling and analysis. Int. J. Prod. Econ., 208, pp. 400--411 (2019)

3. Liagkou, V., Salmas, D., Stylios, C.: Realizing Virtual Reality Learning Environment for Industry 4.0. Procedia CIRP, vol. 79, pp. $712--717$ (2019)

4. Putnik, G., Costa, E., Alves, C. F. V., Shah, V.: Analyzing the correlation between social network analysis measures and performance of students in social network-based engineering education. Int. J. Technol. Des. Ed. 26 (3), pp. $413--437$ (2016)

5. Stadnicka, D, Litwin, P, Antonelli, D.: Human factor in intelligent manufacturing systems knowledge acquisition and motivation. Procedia CIRP, vol. 79, pp. 718--723 (2019)

6. Camarinha-Matos L.M. Afsarmanesh H.: On reference models for collaborative networked organizations, Int. J. Prod. Res. 46:9, 2453--2469 (2008)

7. Juran, J. M., Godfrey, A. B.: Total Quality Management, McGraw-Hill Companies (2001)

8. Pande, P. S., Neuman, R. P., Cavanagh, R.: The Six Sigma Way: How to Maximize the Impact of Your Change and Improvement Efforts, McGraw-Hill Education (2014)

9. Nakajima, S.: Introduction to TPM: Total Productive Maintenance. Productivity Press (1988)

10. Liker, J. K., Franz, J. K.: The Toyota Way to Continuous Improvement: Linking Strategy and Operational Excellence to Achieve Superior Performance. McGraw-Hill Education (2011)

11. Feld W. M.: Lean Manufacturing: Tools, Techniques, and How to Use Them. St. Lucie Press (2000)

12. Nuhoğlu, H.: The effect of the system dynamics approach on understanding causal relationship skills in science education, Procedia - Social and Behavioral Sciences, vol. 2, 2, pp. 3614--3618 (2010)

13. Forrester, J. W.: Learning through System Dynamics as Preparation for the 21st Century, System Dynamics Review, 32, issue 3-4, pp. 187--203 (2016)

14. Forrester, J. W.: Industrial Dynamics, MIT Press, Cambridge, Mass (1961)

15. Angerhofer, B.J., Angelides, M.C.: System dynamics modeling in supply chain management: Research review, Proc. of the 2000 Winter Simul. Conf., 342--351 (2000)

16. Litwin, P., Jakieła, J., Olech, M.: Dynamic simulation based optimization of information flow in extended enterprise and its impact on business partners production efficiency and stock replenishment. Adv. in manufac. science and technology, 40 (1) (2016)

17. Robinson, S.: Discrete-event Simulation: from the Pioneers to the Present, What Next? J. of the Operational Research Society, 56(6) (2005)

18. Fiallos, A., Ochoa, X.: Discrete event simulation for student flow in academic study periods, Twelfth Latin American Conference on Learning Technologies (LACLO) (2017)

19. Gang, L. An Shengmin, Liao Junjun: The Optimization and Simulation of Automobile Spread Production Line, Industrial Engineering, vol. 11, no. 6 (2009)

20. Wu, G., Yao, L., Yu, S.: Simulation and optimization of production line based on FlexSim, Chinese Control And Decision Conference (CCDC) (2018)

21. Tokgöz, E.: Industrial Engineering and Simulation Experience Using Flexsim Software, Computers in Education Journal, vol. 8, 4 (2017)

22. Rostkowska, M.: Simulation of production lines in the education of engineers: how to choose the right software? Management and Production Engineering Review, vol. 5, no. 4 (2014)

23. Holweg M., Disney S., Hines P., Naim M.: Towards responsive vehicle supply: A simulation-based investigation into automotive scheduling systems, J. Oper. Manage, vol. 23 , pp. 507--530, 2005. 